\title{
Attitudes Among Dermatologists Regarding Actinic Keratosis Treatment Options
}

\author{
Gaia Moretta \\ IDI-IRCCS \\ Tonia Samela \\ IDI-IRCCS
}

Francesca Sampogna

IDI-IRCCS

Francesco Ricci

IDI-IRCCS

\section{Fabio Carlesimo \\ IDI-IRCCS}

\section{Annarita Panebianco}

IDI-IRCCS

\section{Angelo Massimiliano D’Erme}

Livorno Hospital

Giovanni Di Lella

IDI-IRCCS

\section{Sabatino Pallotta}

IDI-IRCCS

Elena Dellambra

IDI-IRCCS

\section{Damiano Abeni}

IDI-IRCCS

Luca Fania ( $\nabla$ I.fania@idi.it)

IDI-IRCCS

\section{Research Article}

Keywords: skin tumor, skin cancer, non-melanoma, dermatology, therapy, actinic keratosis, photodynamic therapy, 5Fluorouracil, diclofenac sodium, imiquimod, ingenol mebutate, cryotherapy.

Posted Date: September 9th, 2021

DOI: https://doi.org/10.21203/rs.3.rs-882531/v1

License: 우 (i) This work is licensed under a Creative Commons Attribution 4.0 International License. Read Full License

Version of Record: A version of this preprint was published at Dermatology Reports on January 31st, 2022. See the published version at https://doi.org/10.4081/dr.2022.9392. 


\section{Abstract}

Actinic keratosis (AK) is a carcinoma in situ that may progress into an invasive squamous cell carcinoma and, previously, it has been considered as a pre-cancerous lesion. Its prevalence is increasing, and it has been estimated worldwide to range between $1 \%$ and $44 \%$ of the adult population. The main risk factors for AK are advanced age, fair skin phototype and cumulative sun exposure. Treatment of AK consists of lesion-directed treatment to target single lesions (i.e., cryotherapy, curettage, electrocoagulation, and laser therapy) or field therapy to treat multiple AKs (i.e., photodynamic therapy (PDT), 5- Fluorouracil (5-FU), diclofenac sodium (DIC), imiquimod (IMQ), ingenol mebutate (Ing Meb)). The choice of therapy depends on the number and localization of AKs, patient's condition, and the patient's tolerability and compliance. In this survey we provided data from one hundred and ten Italian dermatologists regarding knowledge and attitude towards different therapeutic approaches specific for AK. In our study, we observed that the most frequent treatments for AK are cryotherapy and PDT while surgery and laser therapy are the less frequently utilized. The most frequent topical therapies utilized are DIC and IMQ 3.75\% cream compared to IMQ 5\% cream, Ing Meb, and 5-FU. Choice the correct treatment for AK can be challenging but the adherence to therapy plays a key role to obtain good results. Considering the high and progressive increase in incidence of $A K$, it is crucial to improve the knowledge of different therapeutic approaches among dermatologists.

\section{Introduction}

Actinic keratosis (AK) is mostly considered as a carcinoma in situ that may evolve into an invasive squamous cell carcinoma (SCC) (Werner et al. 2015). Previously, AK has been defined as a pre-cancerous lesion and still now there are some controversies regarding its real definition. The prevalence of AK has been estimated worldwide to be between $1 \%$ and $44 \%$ of the adult population (Naldi et al., 2006). The main risk factors for developing AK are advanced age, fair skin phototype and cumulative sun exposure (Traianou et al., 2012). In addition, the prevalence of AK is higher in men than women due to greater UV exposure in men, mainly on the scalp. In the European population aged > 70 years, the prevalence of AK has been estimated to be $34 \%$ in men and $18 \%$ in women (Dirschka et al., 2017). Currently the incidence of AK is increasing due to the higher life expectancy and to the inappropriate sun exposure behaviors.

The clinical features of AK are variable. More frequently it is a pink macule or plaque with fine desquamation, flat or hyperkeratotic. Sometimes AK is pigmented, especially when it appears on the face or on the scalp. Considering Olsen's classification, there are three grades of AK based on the intraepithelial location of atypical keratinocytes (Schmitz et al., 2016). AK I and II are superficial lesions that could spontaneously regress, while AK III, is a hyperkeratotic lesion with atypical keratinocytes involving the entire epidermis and may evolve to invasive SCC.

AKs could be multiple and usually appear on areas chronically exposed to UV radiation defined as field of cancerization. In this area, the skin surrounding the AKs is characterized by subclinical changes displaying the same genetic changes found in the lesion itself (Stockfleth, 2017). The diagnosis of AK is mainly clinical and/or dermoscopic but, in specific cases, reflectance confocal microscopy can be utilized to distinguish it from other benign or malignant tumors. In uncertain cases, when the progression into invasive SCC is suspected, a skin biopsy with histological examination is recommended.

Two therapeutic approaches are available to treat AK: lesion-directed treatment to target single lesions or field therapy to treat multiple AKs and the surrounding areas of photodamaged skin (Goldenberg, 2017; Werner et al., 2015). In case of single lesions ( $\geq 1$ and $\leq 5$ lesions), ablative therapy is preferred and includes cryotherapy, curettage, electrocoagulation, and laser therapy. Other treatments such as piroxicam could be utilized for AK single lesions (Puviani et al. 2017)

A field therapy, consisting of topical treatments with or without photodynamic therapy (PDT), is recommended to treat multiple AKs ( $\geq 6$ lesions) and the underlying area of photodamage. According to current international recommendations, 
field treatments include: $4 \%, 5 \%, 0.5 \%$ ( $\pm 10 \%$ salicylic acid) 5- Fluorouracil (5-FU), diclofenac sodium (DIC; 3\%), imiquimod (IMQ; 2.5\%, 3.75\%, 5\%), ingenol mebutate (Ing Meb; 0.015\%, 0.05\%), 5-aminolevulinic acid (ALA) plus PDT and methyl aminolevulinate (MAL; $16.0 \%, 16.8 \%$ ) plus PDT. The choice of therapy depends on the number and localization of AKs, patient's condition, and the patient's tolerability and compliance. (De Berker et al., 2017; Werner et al., 2015)

The aim of this study was to evaluate the knowledge and attitude among dermatologists towards different therapeutic approaches specific for AK.

\section{Material And Methods}

The present data were extracted from a survey conducted on a sample of dermatologists recruited by other dermatologists according to a snowball sampling procedure.

The study was approved by Institutional Ethical Committee of IDI-IRCCS in Rome (Approval \# 608-1) and was conducted in accordance with the Declaration of Helsinki. A questionnaire was sent by email to all clinicians, describing the purpose of the study. Dermatologists who agreed to participate signed a written informed consent before starting the study. Data were collected from June 16th, 2020 to August 1st, 2020. The questionnaire consisted of two parts.

The first part included personal data from participant: gender, age, number of years since they finished dermatology residency $(<10,10-19, \geq 20)$, geographical area (Northern, Central, or Southern Italy), workplace (hospital, university/research hospital, local health department, private practice) (Table 1). 
Table 1

Description of the sample and relationship between sociodemographic features and therapeutic choices for AK (N.110)

\begin{tabular}{|c|c|c|c|c|c|c|c|}
\hline \multicolumn{8}{|c|}{$\%$ of used treatments for AK } \\
\hline \multicolumn{3}{|c|}{ Dermatologists } & Diclofenac*1 & $\begin{array}{l}\text { Imiquimod } \\
3.75 \%{ }^{2}\end{array}$ & Ingenolo*3 & Piroxicam $\star^{4}$ & Laser $\star 5 \star 6$ \\
\hline \multicolumn{2}{|r|}{ column \% } & Overall & 80.0 & 58.2 & 19.1 & 47.3 & 53.6 \\
\hline \multirow[t]{2}{*}{ Sex } & Female & 51.8 & 82.5 & 52.6 & 21.1 & 54.4 & 56.1 \\
\hline & Male & 48.2 & 77.4 & 64.2 & 17.0 & 36.6 & 50.9 \\
\hline \multirow{4}{*}{$\begin{array}{l}\text { Years since } \\
\text { specialization }\end{array}$} & $<10$ & 30.9 & 82.4 & 67.6 & 20.6 & 50.0 & 61.8 \\
\hline & $10-19$ & 25.5 & 86.2 & 65.5 & 24.1 & 69.0 & 62.1 \\
\hline & $20-29$ & 10.9 & 63.6 & 54.5 & 9.1 & 27.3 & 36.4 \\
\hline & $\geq 30$ & 32.7 & 77.8 & 44.4 & 16.7 & 3.3 & 44.4 \\
\hline \multirow[t]{3}{*}{ Area } & Northern & 22.7 & 88.0 & 76.0 & 8.0 & 41.9 & 72.0 \\
\hline & Central & 56.4 & 72.6 & 56.5 & 19.4 & 68.0 & 48.4 \\
\hline & Southern & 20.9 & 91.3 & 43.5 & 30.4 & 39.1 & 47.8 \\
\hline \multicolumn{8}{|c|}{${ }^{\star 1}$ Diclofenac $x$ Area $=\chi^{2}$ M-H Treand: $0.023 p<0.05$} \\
\hline \multicolumn{8}{|c|}{${ }^{\star 3}$ Ingenolo $x$ Area: $\chi^{2} M-H$ Treand $=0.03, p<0.05$} \\
\hline \multicolumn{8}{|c|}{$\begin{array}{l}\left.\star^{4} \text { Piroxicam x yrs of specialization (" }<10 \text { to } 19 \text { " group vs the other groups " } 20->30 "\right): \chi^{2} \text { mid-P }=0.006 p \\
<0.05\end{array}$} \\
\hline
\end{tabular}

The second part consisted in specific questions regarding knowledge and attitude towards different therapeutic approaches for AK (Table 2). 
Table 2

Description of the answers of dermatologists to the question concerning AK therapy approaches (N.110)

\begin{tabular}{|c|c|c|c|c|c|c|c|c|}
\hline \multirow{2}{*}{$\begin{array}{l}\text { THERAPEUTIC } \\
\text { APPROACHES }\end{array}$} & \multicolumn{8}{|c|}{ “IN PERCENTAGE, FOR EVERY 100 NEW AK, I PRESCRIBED*” } \\
\hline & NEVER & $\begin{array}{l}5 \% \text { OF } \\
\text { TIMES }\end{array}$ & $\begin{array}{l}10 \% \text { OF } \\
\text { TIMES }\end{array}$ & $\begin{array}{l}25 \% \text { OF } \\
\text { TIMES }\end{array}$ & $\begin{array}{l}50 \% \text { OF } \\
\text { TIMES }\end{array}$ & $\begin{array}{l}75 \% \text { OF } \\
\text { TIMES }\end{array}$ & $\begin{array}{l}100 \% \text { OF } \\
\text { TIMES }\end{array}$ & \%MISSED \\
\hline SURGERY & 53.7 & 28.2 & 12.7 & 3.6 & 0.9 & / & / & 0.9 \\
\hline CRYOTHERAPY & 10 & 10 & 7.3 & 10 & 29.1 & 26.4 & 7.3 & / \\
\hline $\begin{array}{l}\text { PHOTODYNAMIC } \\
\text { THERAPY }\end{array}$ & 17.3 & 13.6 & 20.9 & 17.3 & 20.9 & 10.0 & / & / \\
\hline IMIQUIMOD 5\% & 36.4 & 18.2 & 15.5 & 23.6 & 5.5 & 0.9 & / & / \\
\hline IMIQUIMOD 3.75\% & 41.8 & 11.8 & 14.5 & 18.2 & 9.1 & 4.5 & / & / \\
\hline DICLOFENAC & 20.0 & 11.8 & 15.5 & 28.2 & 14.5 & 10.0 & / & / \\
\hline 5-FLUOROURACILE & 40.9 & 19.1 & 17.3 & 13.6 & 7.3 & 1.8 & / & / \\
\hline INGENOLO & 80.9 & 6.4 & 6.4 & 5.5 & 0.9 & / & / & / \\
\hline PIROXICAM & 52.7 & 23.6 & 13.6 & 7.3 & 2.7 & / & / & / \\
\hline $\begin{array}{l}\text { CURATTAGE- } \\
\text { LASER }\end{array}$ & 46.4 & 24.5 & 15.5 & 8.2 & 4.5 & 0.9 & / & / \\
\hline
\end{tabular}

Data were described as numbers, percentages, and frequency rates. Results were compared in different subgroups of participants, according to gender, years since finishing dermatology training, geographical area, and workplace, using the chi-square test. Data were analyzed using IBM SPSS Statistics for Windows, Release 26.0.0.1 (IBM Corp., Armonk, NY, USA).

\section{Results}

The study participants were one hundred and ten dermatologists. There were 57 women (51.8\%) and 53 (48.2\%) men. More than $30 \%$ of them had finished dermatology training since less than 10 years, $25.5 \%$ since 10 to 19 years, and $43.6 \%$ in the last 20 years or more. The description of the study population and trends in therapeutic choices are shown in Tables 1 and 2.

Concerning therapeutic approaches, the most frequent are cryotherapy and PDT. Some dermatologists (26.4\%) prescribed cryotherapy for $75 \%$ of AK cases whereas others (29.1\%) for $50 \%$ of AK cases. As for PDT, $20.9 \%$ of participants prescribed it for $50 \%$ of AK cases, while $17.3 \%$ never used it.

Surgery and laser therapy are the less frequent utilized therapeutic options. Notably, $53.7 \%$ of participants never prescribed surgery. Similarly, $46.4 \%$ of dermatologists never prescribed laser therapy for AK. However, laser therapy is utilized for $5 \%$ of AKs by $24.5 \%$ of participants and surgery by $28.2 \%$.

As for topical therapy, the results are variable. The most frequent topical therapies utilized in 50\% of AKs are IMQ $3.75 \%$ cream prescribed by $9.1 \%$ of participants and DIC used by $14.5 \%$ of them. Despite this, $41.8 \%$ of dermatologists never prescribed IMQ $3.75 \%$ and $20.0 \%$ of them never used DIC. Moreover, IMQ $5 \%$ cream is prescribed by $5.5 \%$ of participants for $50 \%$ of AKs and by $23.6 \%$ of them for $25 \%$ of AKs. Among dermatologists who participated in the survey, $80.9 \%$ never used Ing Meb and 52.7\% never prescribed piroxicam. Few dermatologists (6.4\%) prescribe Ing Meb for $5 \%$ of AKs while 
$23.6 \%$ of them prescribed piroxicam. As regards $5-\mathrm{FU}, 7.3 \%$ of dermatologists prescribed it for $50 \%$ of $\mathrm{AKs}$ and $40.9 \%$ of them never used it.

Furthermore, laser therapy is more utilized in Northern (72\%) compared to Central (48.4\%) and Southern Italy (47.8\%) while Ing Meb is more used in Southern (30.4\%) compared to Northern (8.0\%) and Central (19.4\%) Italy (Table 1).

Considering the years since specialization, dermatologists who had finished Dermatology training since less than 10 years prescribed IMQ 3.75\% more than older colleagues (> 10 ys. $=67.6 \%, 10-19$ ys. $=65.5 \%, 20-29$ ys. $=54.5 \%, \geq 30$ ys. $=44.4 \%$ ). Moreover, piroxicam is mainly prescribed by younger dermatologists (>10 ys. $=50 \%, 10-19$ ys. $=69.0 \%$ ) compared to older colleagues (20-29 ys. $=27.3 \%, \geq 30$ ys. $=3.3 \%)$.

\section{Discussion}

In our survey, cryotherapy is the most used treatment by dermatologists for AK. Cryotherapy is recommended by guidelines to treat single AK lesion (Eisen et al.2021)(Werner et al., 2015) but sometimes it can be used also to treat multiple AKs, mainly in the elderly with photodamaged skin. PDT, which is preferable as field therapy to treat multiple AKs, is prescribed by $20.9 \%$ dermatologists for $50 \%$ of AKs and by $10 \%$ of them for $75 \%$ of AKs. However, in our sample, $17.3 \%$ of participants did not prescribed PDT probably because not all medical institutions have facilities to dispense this therapy or because some dermatologists are not confident to use traditional PDT or day light PDT. Another reason could be that PDT is an expensive treatment and, dependently from National Health System, there could be few hospitals that offer it without any payments (Lee et al., 2020).

Surgery, instead, is the less common therapeutic option: $53.7 \%$ of dermatologists never prescribed it and $28.2 \%$ used it only for $5 \%$ of AK cases. In fact, surgery is not recommended by guidelines to treat AK but it is needed in uncertain cases that could progress to an invasive SCC (Chetty et al., 2015; Newlands et al., 2016).

Regarding laser therapy, about $50 \%$ of dermatologists never require it and about $35 \%$ prescribed it in $5-15 \%$ of AKs. A reason to explain this result is that laser therapy is more expensive compared to cryotherapy. Besides, CO2 laser ablation is not superior to cryotherapy for the treatment of isolated AKs of the face and of the scalp, as reported in a randomized clinical trial (Zane et al., 2014).

As regards to topical therapeutic options, the results are variable. DIC was the most prescribed topical product for AK. About $80 \%$ of interviewed dermatologists used it for $A K$ and in particular about $25 \%$ prescribed it for $50-75 \%$ of $A K$ cases. These results can be explained due to the efficacy and safety of DIC. It could be quite well tolerated also by elderly patients because side effects, such as mild erythema or itching, generally are rarer compared to IMQ (Dianzani et al., 2020).

IMQ is present in two different percentage (5\% and 3.75\%) in Italy. Our survey showed that 3.75\% IMQ is more prescribed than $5 \%$ IMQ. Specifically, for $50-75 \%$ of AKs, $3.75 \%$ IMQ is prescribed by about $15 \%$ of dermatologists while $5 \%$ IMQ is used by about $6 \%$ of them. Both topical immunotherapy with IMQ (i.e., 3.75\% and 5\%) are effective to treat the whole cancerization field but they cannot be used in patients who have received an organ transplant. According to international guidelines regarding AK therapies, IMQ 5\% has to be applied 3 days a week for 6 weeks while IMQ 3.75\% is used for 14 consecutive days a month for 2 months. The different posology and the lower side effects for IMQ 3.75\% could explain the major used of this percentage of IMQ as showed in our data.

Regarding 5-FU, a recent systematic review and network meta- analysis reported that this topical therapy has the best efficacy and safety profile compared with other field-directed therapies for AKs (Ezzedine et al., 2020). 5-FU cream has been approved for the treatment of non-hyperkeratotic, non-hypertrophic AK (Dohil, 2016). Despite this, in our sample only $60 \%$ of interviewed dermatologists prescribed 5 -FU, and only $9 \%$ of them utilized 5 -FU for $50-75 \%$ of AKs. $40 \%$ of

Page 6/9 
participants have never used 5FU. These limited used of this topical therapy could be due to the recent introduction of 5FU in Italy for the treatment of AK.

Moreover, in our sample about $80 \%$ of participants declared not to use Ing Meb. This topical therapy has been approved by FDA for multiple non hypertrophic and non- hyperkeratotic AKs on a field of cancerization in January 2012 (Costa et al., 2015). Despite it could provoke moderate-severe side effects after the treatment, it was acceptable for patients for its efficacious and because it had to be used for only 3 days on the scalp and for 2 days on the trunk (Ricci et al., 2016; Elías et al., 2016). However, in 2020 the market authorization for Ing Meb in the European Union was withdrawn because this drug was proven to be associated to an increase of skin cancer (Tzogani et al., 2014).

As regards piroxicam, about $50 \%$ of dermatologists declared not to prescribe it and about $35 \%$ used it for $5-10 \%$ of AKs. These data can be understandable considering that this product is utilized for the treatment of AK or to prevent the development of new AK on photodamaged area, but it is not recommended by European and Italian Guidelines (Werner et al. 2015; Moscarella et al. 2020). Furthermore, the multivariable model showed that dermatologists who had finished their training more recently were more used to prescribe piroxicam than the older ones.

It is interesting to observe that laser therapy is more utilized for AKs in Northern compared to Central Italy probably due for the major availability in the first region. Otherwise, DIC is more used in Southern Italy while IMQ is prescribed more in Northern Italy. This difference could be due to the fact that dermatologists from Southern Italy prefer to use DIC because it gives less side effects than IMQ.

The results of our study seems in line with a recent Italian consensus (Moscarella et al., 2020) and with European guidelines (Heppt et al., 2020; Werner et al., 2015). Cryotherapy is the most used treatment for patients with few AK (less than 5 scattered AKs or less than 3 AKs in an area of $25 \mathrm{~cm}^{2}$ ), while, PDT and IMQ cream are preferred for patients with multiple AKs ( 5 or more AKs or 3 or more AKs in an area of $25 \mathrm{~cm}^{2}$ ) (Moscarella et al., 2020).

Considering that AK could be a chronic disease, most dermatologists are used to have a combination approach with multiple treatment for AK (Dirschka et al., 2017). Specifically, a field therapy with IMQ 3.75\% can be prescribed after cryotherapy to obtain a better clearance of AK, and similarly cryotherapy can follow PDT or other topical treatment.

The results of our survey confirm that the real-world therapeutic approach is variable, and the goal of treatment is AK reduction and long-term disease control to prevent SCC development. The challenge for every dermatologist is to choose the proper treatment for every patient, considering not only the clinical presentation and number of AK, but also patient's condition such as age, comorbidity, immunosoppression and adherence to treatment (Heppt et al., 2020).

A limitation of our study is the restricted number of the considered dermatologists and the fact that the questionnaire did not distinguished the treatment for singles AKs or for multiple AKs in a field of cancerization.

\section{Conclusions}

We found that the most frequently used treatments for AKs by Italian dermatologists are cryotherapy, PDT and topical agents, such as DIC and IMQ. Our results highlight that choice the appropriate treatment for AK can be challenging and should be adopted to every patient because adherence to therapy plays a key role to obtain good results. Besides, AK should be considered a chronic disease in patients with severe photodamage and different therapies could be used consecutively to obtain a complete skin clearance and to prevent the development of SCC.

\section{Declarations}


Funding: This study was mainly supported by the "Progetto Ricerca Corrente - RC4.3 2019" of the Italian Ministry of Health, Rome, Italy.

\section{Acknowledgments}

This study was mainly supported by the "Progetto Ricerca Corrente - RC4.3 2019" of the Italian Ministry of Health, Rome, Italy.

The Authors thank the "Associazione Dermatologi Ospedalieri Italiani" (ADOI) for the collaboration in the survey.

\section{References}

1. Chetty, P., Choi, F., \& Mitchell, T. (2015). Primary care review of actinic keratosis and its therapeutic options: a global perspective. Dermatology and Therapy, 5(1), 19-35.

2. Costa, C., Scalvenzi, M., Ayala, F., Fabbrocini, G., \& Monfrecola, G. (2015). How to treat actinic keratosis? An update. Journal of Dermatological Case Reports, 9(2), 29.

3. De Berker, D., McGregor, J. M., Mohd Mustapa, M. F., Exton, L. S., Hughes, B. R., McHenry, P. M., Gibbon, K., Buckley, D. A., Nasr, I., \& Duarte Williamson, C. E. (2017). British Association of Dermatologists' guidelines for the care of patients with actinic keratosis 2017. British Journal of Dermatology, 176(1), 20-43.

4. Dianzani, C., Conforti, C., Giuffrida, R., Corneli, P., di Meo, N., Farinazzo, E., Moret, A., Magaton Rizzi, G., \& Zalaudek, I. (2020). Current therapies for actinic keratosis. International Journal of Dermatology, 59(6), 677-684.

5. Dirschka, T., Gupta, G., Micali, G., Stockfleth, E., Basset-Séguin, N., Del Marmol, V., Dummer, R., Jemec, G. B. E., Malvehy, J., \& Peris, K. (2017). Real-world approach to actinic keratosis management: practical treatment algorithm for office-based dermatology. Journal of Dermatological Treatment, 28(5), 431-442.

6. Dohil, M. A. (2016). Efficacy, Safety, and Tolerability of 4\% 5-Fluorouracil Cream in a Novel Patented Aqueous Cream Containing Peanut Oil Once Daily Compared With 5\% 5-Fluorouracil Cream Twice Daily: Meeting the Challenge in the Treatment of Actinic Keratosis. Journal of Drugs in Dermatology: JDD, 15(10), 1218-1224.

7. Elías, I., Ortega-Joaquín, N., de la Cueva, P., del Pozo, L. J., Moreno-Ramírez, D., Boada, A., Aguilar, M., Mirada, A., Mosquera, E., Gibbons, C., \& Oyagüez, I. (2016). Cost-Effectiveness and Cost-Utility Analysis of Ingenol Mebutate Versus Diclofenac 3\% and Imiquimod 5\% in the Treatment of Actinic Keratosis in Spain. Actas Dermo-Sifiliográficas (English Edition), 107(6), 498-508. https://doi.org/https://doi.org/10.1016/j.adengl.2016.05.022

8. Ezzedine, K., Painchault, C., \& Brignone, M. (2020). Use of complete clearance for assessing treatment efficacy for 5fluorouracil interventions in actinic keratoses: how baseline lesion count can impact this outcome. Journal of Market Access \& Health Policy, 8(1), 1829884. https://doi.org/10.1080/20016689.2020.1829884

9. Goldenberg, G. (2017). Treatment considerations in actinic keratosis. Journal of the European Academy of Dermatology and Venereology, 31, 12-16.

10. Heppt, M. V, Leiter, U., Steeb, T., Amaral, T., Bauer, A., Becker, J. C., Breitbart, E., Breuninger, H., Diepgen, T., \& Dirschka, T. (2020). S3 guideline for actinic keratosis and cutaneous squamous cell carcinoma-short version, part 1: diagnosis, interventions for actinic keratoses, care structures and quality-of-care indicators. JDDG: Journal Der Deutschen Dermatologischen Gesellschaft, 18(3), 275-294.

11. Lee, C. N., Hsu, R., Chen, H., \& Wong, T. W. (2020). Daylight Photodynamic Therapy: An Update. Molecules (Basel, Switzerland), 25(21). https://doi.org/10.3390/molecules25215195

12. Moscarella, E., Di Brizzi, E. V., Casari, A., De Giorgi, V., Di Meo, N., Fargnoli, M. C., Lacarrubba, F., Micali, G., Pellacani, G., \& Peris, K. (2020). Italian expert consensus paper on the management of patients with actinic keratoses. Dermatologic Therapy, 33(6), e13992. 
13. Naldi, L., Chatenoud, L., Piccitto, R., Colombo, P., Placchesi, E. B., \& La Vecchia, C. (2006). Prevalence of actinic keratoses and associated factors in a representative sample of the Italian adult population: Results from the Prevalence of Actinic Keratoses Italian Study, 2003-2004. Archives of Dermatology, 142(6), 722-726.

14. Newlands, C., Currie, R., Memon, A., Whitaker, S., \& Woolford, T. (2016). Non-melanoma skin cancer: United Kingdom National Multidisciplinary Guidelines. The Journal of Laryngology \&amp; Otology, 130(S2), S125-S132. https://doi.org/10.1017/S0022215116000554

15. Ricci, F., Tambone, S., Neri, L., Fania, L., Piccioni, A., Guerriero, C., Fargnoli, M. C., \& Peris, K. (2016). Real-life efficacy and safety of ingenol mebutate for the treatment of actinic keratosis of the face and scalp: A single arm retrospective study. Journal of Dermatological Treatment, 27(6), 525-530.

16. Schmitz, L., Kahl, P., Majores, M., Bierhoff, E., Stockfleth, E., \& Dirschka, T. (2016). Actinic keratosis: correlation between clinical and histological classification systems. Journal of the European Academy of Dermatology and Venereology, 30(8), 1303-1307. https://doi.org/https://doi.org/10.1111/jdv.13626

17. Stockfleth, E. (2017). The importance of treating the field in actinic keratosis. Journal of the European Academy of Dermatology and Venereology, 31(S2), 8-11. https://doi.org/https://doi.org/10.1111/jdv.14092

18.

19. Puviani M, Galloni C, Marchetti S, Sergio Pavone P, Lovati S, Pistone G, Caputo V, Tilotta G, Scarcella G, Campione E, Diluvio L, Garofalo V, Bianchi L, Milani M. (2017) Efficacy of a film-forming medical device containing sunscreen (50+) and piroxicam $0.8 \%$ in actinic keratosis and field cancerization: a multicenter, assessor-blinded, 3 month trial. Curr Med Res Opin. 2017 Jul;33(7):1255-1259. doi: 10.1080/03007995.2017.1313212.

20.

21. Traianou, A., Ulrich, M., Apalla, Z., De Vries, E., Bakirtzi, K., Kalabalikis, D., Ferrandiz, L., Ruiz-de-Casas, A., MorenoRamirez, D., \& Sotiriadis, D. (2012). Risk factors for actinic keratosis in eight European centres: a case-control study. British Journal of Dermatology, 167, 36-42.

22. Tzogani, K., Nagercoil, N., Hemmings, R. J., Samir, B., Gardette, J., Demolis, P., Salmonson, T., \& Pignatti, F. (2014). The European Medicines Agency approval of ingenol mebutate (Picato) for the cutaneous treatment of nonhyperkeratotic, non-hypertrophic actinic keratosis in adults: Summary of the scientific assessment of the Committee for Medicinal Products for Human Use (CHMP). European Journal of Dermatology, 24(4), 457-463.

https://doi.org/10.1684/ejd.2014.2368

23. Werner, R. N., Stockfleth, E., Connolly, S. M., Correia, O., Erdmann, R., Foley, P., Gupta, A. K., Jacobs, A., Kerl, H., \& Lim, H. W. (2015). Evidence-and consensus-based (S3) guidelines for the treatment of actinic keratosis-International League of Dermatological Societies in cooperation with the European Dermatology Forum-short version. Journal of the European Academy of Dermatology and Venereology, 29(11), 2069-2079.

24. Zane, C., Facchinetti, E., Rossi, M. T., Specchia, C., Ortel, B., \& Calzavara-Pinton, P. (2014). Cryotherapy is preferable to ablative CO 2 laser for the treatment of isolated actinic keratoses of the face and scalp: a randomized clinical trial. British Journal of Dermatology, 170(5), 1114-1121. 